\title{
Effect of Individualized Progesterone Supplementation for Luteal Support in Frozen-Thawed Cycles on Pregnancy Outcomes
}

\author{
Gulsen DOGAN DURDAG', Gizem BEKTAS ${ }^{2}$, Esengul TURKYILMAZ ${ }^{3}$, Halime GOKTEPE ${ }^{4}$, \\ Meltem SONMEZER ${ }^{5}$, Yavuz Emre SUKUR ${ }^{6}$, Batuhan OZMEN ${ }^{6}$, Cem ATABEKOGLU6 ${ }^{6}$ Murat SONMEZER ${ }^{6}$ \\ Adana, Turkey
}

\section{ABSTRACT}

OBJECTIVE: In frozen-thawed embryo transfer cycles, preparing a synchronous endometrium for the embryo is essential. The aim of this study is to provide individualized luteal support in hormonally replaced frozen-thawed embryo transfer cycles and to evaluate mid-luteal serum progesterone levels and pregnancy outcomes.

STUDY DESIGN: In this prospective cohort study, 30 patients were included in a university hospital in a six month period. Serum progesterone level on embryo transfer day was monitored, and if it was found to be below the lower limits defined by previous studies $(10 \mathrm{ng} / \mathrm{mL})$, additional $100 \mathrm{mg}$ intramuscular micronized progesterone was administered once. Mid-luteal progesterone levels and pregnancy outcomes were recorded.

RESULTS: There was no significant difference between mid-luteal progesterone levels of the patients whose transfer day progesterone was above and below $10 \mathrm{ng} / \mathrm{mL}(p=0.481)$. Although the clinical pregnancy rate tended to be higher in patients whose mid-luteal progesterone was above $10 \mathrm{ng} / \mathrm{mL}$, it was also not statistically significant.

CONCLUSION: This is the first study in which vaginal progesterone treatment was supported by intramuscular progesterone according to serum progesterone values for the purpose of individualized progesterone support. A significant difference was not found in pregnancy outcomes. However, further studies are required to optimize management and improve pregnancy rates in hormonally treated frozen-thawed embryo transfer cycles.

Keywords: Frozen-thawed cycles, In vitro fertilization, Luteal support, Pregnancy rate, Progesterone Gynecol Obstet Reprod Med 2022;28(1):50-55

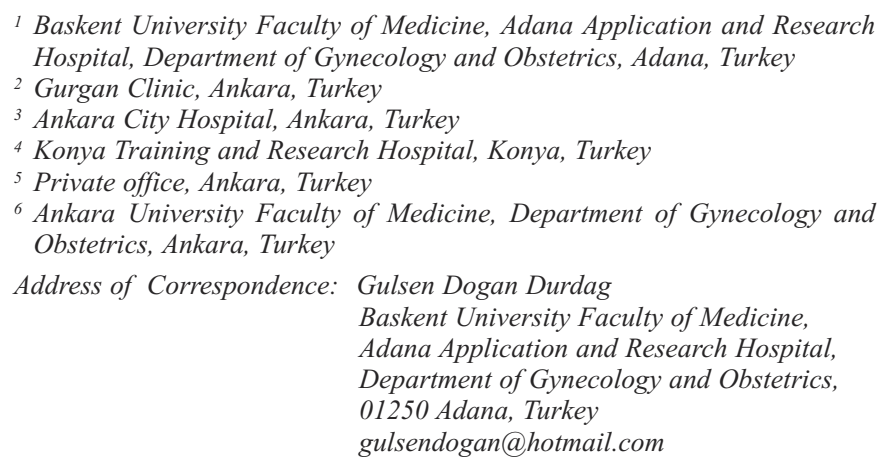

Submitted for :Publication 01.07.2020 Revised for: Publication 23.10.2020

Accepted for Publication: 03.11.2020 Online Puplished: 31.12.2020

ORCID IDs of the authors: GDD: 0000-0002-5064-5267

GB: 0000-0002-7527-2110 ET: 0000-0003-0873-7528

$H G$ : 0000-0002-5026-3680 MS: 0000-0002-5363-474X

YES: 0000-0003-0815-3522 BO: 0000-0002-4504-669X

CA: 0000-0003-0264-0709 MS: 0000-0001-6101-1414

\begin{tabular}{|c|c|}
\hline \multirow{3}{*}{ 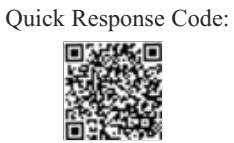 } & Access this article online \\
\hline & $\begin{array}{l}\text { Website: www.gorm.com.tr } \\
\text { e- mail: info@gorm.com.tr }\end{array}$ \\
\hline & DOI:10.21613/GORM.2020.1122 \\
\hline
\end{tabular}

How to cite this article: Dogan Durdag G. Bektas G. Turkyilmaz E. Goktepe H. Sonmezer M. Sukur YE. Ozmen B. Atabekoglu CV. Sonmezer M. Effect of Individualized Progesterone Supplementation for Luteal Support in FrozenThawed Cycles on Pregnancy Outcomes. Gynecol Obstet Reprod Med. $2022 ; 28(1): 50-55$

\section{Introduction}

Improvement in cryopreservation and vitrification techniques enables achieving successful frozen-thawed embryo transfer (FET) outcomes. In these cycles, while embryo quality and appropriate freezing and thawing protocols are crucial, transferring the embryo to a prepared endometrium for a successful implantation is important as well. Preparing a receptive endometrium for the embryo substantially affects the pregnancy rates. There is not a definite protocol that is suggested to increase the success of FET cycles in current literature, though natural cycles or artificial cycles with hormonal replacement can be used (1). Several studies have been conducted to find the proper time and dosage of hormone replacement to find the optimal period of endometrial receptivity. Certain levels of serum progesterone during the luteal phase are reported to affect pregnancy rates, and individualized luteal phase support is suggested to obtain these levels (2$5)$. As for studies comparing vaginal and intramuscular progesterone administration for the optimization of serum progesterone levels, different outcomes are reported (6-8). In a recent study, which assessed the association between vaginal progesterone dose adjustment for individualized luteal phase support 
and pregnancy results, the importance of monitoring serum progesterone levels is emphasized (9).

The aim of this study was to monitor serum progesterone levels in early and mid-luteal phases of hormonally replaced FET cycles; and to administer additional intramuscular progesterone on embryo transfer day, where serum progesterone level was below the threshold $(<10 \mathrm{ng} / \mathrm{mL})$ defined by previous studies $(3,9,10)$. We further assessed its effect on midluteal serum progesterone levels and the relation of these values with clinical pregnancy rates.

\section{Material and Method}

This prospective cohort study was conducted at the In Vitro Fertilization (IVF) Unit of a university hospital. Thirty patients undergoing hormone replaced frozen-thawed embryo cycles using oral estradiol and vaginal progesterone were enrolled between April 2019 and October 2019. Patients who were under 45 years old, who did not have any systemic disease, and who had one of the following infertility diagnoses were included; unexplained infertility, diminished ovarian reserve, polycystic ovary syndrome, tubal factor, or mild/moderate male factor. Patients who underwent any uterine surgery, or who had Müllerian anomaly, hydrosalpinx, moderate/severe endometriosis, or recurrent implantation failure were excluded from the study. The diminished ovarian reserve was defined as $\mathrm{AMH}<1 \mathrm{ng} / \mathrm{mL}$ and antral follicle count $<7$ at both ovaries on ultrasound examination (9). One cycle of 30 patients who had appropriate criteria and consented to study was included. Age and body mass index of the patients, infertility cause, the reason for embryo freezing, and grade of the embryos were recorded. Estradiol (Estrofem ${ }^{\circledR}, 2 \mathrm{mg}$ oral tablet, Novo Nordisk Health Products, Denmark) was started on the second or third day of the menstrual cycle in all patients at doses of $2 \mathrm{mg}$ /day for seven days and increased to $4 \mathrm{mg}$ /day thereafter, providing all patients to receive estradiol for at least 12 days before progesterone administration. During the treatment, endometrial thickness was assessed by consecutive vaginal ultrasound measurements, and micronized progesterone (Crinone ${ }^{\circledR} 8 \%$ Vaginal Gel, Merck, Germany) was started twice a day intravaginally as soon as endometrial thickness $>8 \mathrm{~mm}$, serum E2 $>100 \mathrm{pg} / \mathrm{mL}$, and progesterone $<1.5 \mathrm{ng} / \mathrm{mL}$ was provided. Day 3 embryo transfer was performed on day 4 and day 5/6-blastocyst transfer was performed on day 6 of progesterone administration. Endometrial thickness was re-evaluated by abdominal ultrasound on transfer day. All embryo transfer procedures were performed under ultrasound guidance and a single embryo transfer was performed for each patient.

Serum progesterone values were measured before starting progesterone administration, on embryo transfer day (early luteal phase), and 3 or 5 days after embryo transfer ( $8^{\text {th }}$ day of progesterone administration) (mid-luteal phase). If serum progesterone on embryo transfer day was below the lower lim- its $(10 \mathrm{ng} / \mathrm{mL})$, one dose of additional $100 \mathrm{mg}$ intramuscular progesterone (Progestan ${ }^{\circledR} 50 \mathrm{mg} / \mathrm{mL}$ IM, Kocak Farma, Istanbul) was administered. Patients were classified into two groups according to a predefined progesterone threshold of 10 $\mathrm{ng} / \mathrm{mL}$ on the day of embryo transfer. The effect of additional progesterone administration on mid-luteal serum progesterone and pregnancy rates was evaluated. Clinical pregnancy was defined as the detection of the fetal heartbeat by vaginal ultrasound.

This study was conducted in accordance with the Declaration of Helsinki and was approved by the Institutional Review Board and Ethics Committee of Ankara University Faculty of Medicine (Decision number: i3-121-19). Informed consent for using data was obtained from all patients.

SPSS 23.0 program was used for statistical analysis. Categorical measurements were assessed as number and percent, continuous measurements were summarized as mean and standard deviation. Chi-Square or Fisher test statistics were used to compare categorical variables between groups. To compare continuous variables, distributions were assessed, Student t-test for parametric variables and Mann Whitney $\mathrm{U}$ test for nonparametric variables were used. $p<0.05$ was considered significant for all tests.

\section{Results}

The cause for infertility for 30 patients was as follows; male factor infertility $(n=12)$, unexplained infertility $(n=9)$, diminished ovarian reserve $(\mathrm{n}=4)$, polycystic ovary syndrome $(n=3)$, tubal factor infertility $(n=1)$, and hypogonadotropic hypogonadism $(\mathrm{n}=1)$.

Frozen embryo transfer resulted in clinical pregnancy in 16 of 30 patients $(53.3 \%)$. When patients were classified into two groups according to transfer day progesterone values $(<10 \mathrm{ng} / \mathrm{mL}$ and $\geq 10 \mathrm{ng} / \mathrm{mL})$, characteristics of groups including age, body mass index, cause of infertility, the reason for embryo freezing, number, and grade of embryos were similar between the groups (Table I).

Transfer day progesterone was $\geq 10 \mathrm{ng} / \mathrm{mL}$ in 10 of 16 patients $(62.5 \%)$ with clinical pregnancy, while serum progesterone was $\geq 10 \mathrm{ng} / \mathrm{mL}$ in 8 of 14 patients $(57.1 \%$ ) without pregnancy. No significant difference was found between clinical pregnancy rates according to transfer day progesterone levels, being $<10 \mathrm{ng} / \mathrm{mL}$, or $\geq 10 \mathrm{ng} / \mathrm{mL}$ (Table II).

In 13 of 18 patients $(72.2 \%)$, where transfer day progesterone was $\geq 10 \mathrm{ng} / \mathrm{mL}$, mid-luteal progesterone was $\geq 10$ $\mathrm{ng} / \mathrm{mL}$. In contrast, mid-luteal progesterone was lower than the transfer day progesterone level in 5 patients.

Following additional intramuscular progesterone administration, mid-luteal progesterone was found to be above 10 $\mathrm{ng} / \mathrm{mL}$ in 10 of 12 patients $(83.3 \%)$ where transfer day progesterone was $<10 \mathrm{ng} / \mathrm{mL}$. 
Table I: Demographic features of the groups due to progesterone levels on transfer day

\begin{tabular}{|c|c|c|c|}
\hline & $\begin{array}{l}\text { Transfer day } P G<10 \mathrm{ng} / \mathrm{mL} \\
(\mathrm{n}=12)\end{array}$ & $\begin{array}{l}\text { Transfer day } P G \geq 10 \mathrm{ng} / \mathrm{mL} \\
(\mathrm{n}=18)\end{array}$ & $p$ \\
\hline Age (median (min-max)) & $29(24-33)$ & $31(26-42)$ & 0.113 \\
\hline BMI (median (min-max)) & $23.67(20.83-31.07)$ & $22.58(19.03-36.00)$ & 0.183 \\
\hline \multicolumn{4}{|l|}{ Cause of Infertility } \\
\hline Male factor & 5 & 7 & \\
\hline Unexplained infertility & 2 & 7 & \\
\hline PCOS & 2 & 1 & \\
\hline DOR & 2 & 2 & \\
\hline Tubal factor & 0 & 1 & \\
\hline Hypogonadotropic hypogonadism & 1 & 0 & \\
\hline Embryo stage (D3/D5) & $3 / 9$ & $4 / 14$ & 0.862 \\
\hline
\end{tabular}

PG: Progesterone, BMI: Body mass index, PCOS: Polycystic ovary syndrome, DOR: Diminished ovarian reserve

Table II: Pregnancy rates due to progesterone values at transfer day and $8^{\text {th }}$ day

\begin{tabular}{llll}
\hline & $\begin{array}{l}\text { Pregnancy }(-) \\
(\mathbf{n = 1 4 )}\end{array}$ & $\begin{array}{l}\text { Pregnancy }(+) \\
(\mathbf{n = 1 6 )}\end{array}$ \\
\hline $\mathrm{PG}<10 \mathrm{ng} / \mathrm{mL}$ at transfer day & $50.0 \%$ & $50.0 \%$ & 0.765 \\
$\mathrm{PG} \geq 10 \mathrm{ng} / \mathrm{mL}$ at transfer day & $44.4 \%$ & $55.6 \%$ & $\mathbf{2 8 . 6 \%}$ \\
$\mathrm{PG}<10 \mathrm{ng} / \mathrm{mL}$ at 8 th day & $71.4 \%$ & $\mathbf{6 0 . 9 \%}$ & $\mathbf{0 . 2 0 4}$ \\
$\mathrm{PG} \geq 10 \mathrm{ng} / \mathrm{mL}$ at 8 th day & $39.1 \%$ & & \\
\hline
\end{tabular}

\section{PG: Progesterone}

When two groups were classified according to transfer day serum progesterone, being higher and lower than $10 \mathrm{ng} / \mathrm{mL}$, following intramuscular progesterone in patients whose progesterone was $<10 \mathrm{ng} / \mathrm{mL}$ on transfer day, mean mid-luteal progesterone were not significantly different between the groups $(p=0.481)$.

When mid-luteal progesterone values were considered, 23 patients had progesterone values $>10 \mathrm{ng} / \mathrm{mL}$ and pregnancy was achieved in 14/23 (60.9\%) of these patients. Mid-luteal progesterone was below $10 \mathrm{ng} / \mathrm{mL}$ in 7 patients and pregnancy was achieved only in 2/7 (28.6\%) of these patients. Although the clinical pregnancy rate seemed to be higher in patients where day 8 progesterone was above $10 \mathrm{ng} / \mathrm{mL}$, no statistical significance was noted (Table II). Age, body mass index, number, and grade of embryos were also similar between the groups $(p>0.05)$.

Furthermore, when patients were classified in terms of clinical pregnancy, a significant difference was not found between age, body mass index, cause of infertility, the reason for embryo freezing, number of embryos, embryo quality, initial serum progesterone levels, transfer day progesterone and day 8 progesterone levels (Table III). Embryo grades, all of which were $4 \mathrm{AA}$ and $4 \mathrm{AB}$, were also similar between the groups $(p=0.294)$.

Table III: Features of the groups due to pregnancy achievement

\begin{tabular}{lccc}
\hline & $\begin{array}{c}\text { Pregnancy }(-) \\
(\mathbf{n}=14)\end{array}$ & $\begin{array}{c}\text { Pregnancy }(+) \\
(\mathbf{n = 1 6 )}\end{array}$ & $p$ \\
\hline Age & $31(28-42)$ & $30.50(24-38)$ & 0.981 \\
Body mass index & $22.60(21.19-30.10)$ & $23.12(19.03-36.00)$ & 0.957 \\
PG in the beginning & $0.53(0.20-1.48)$ & $0.62(0.20-1.45)$ & 0.614 \\
PG at transfer day & $10.32(2.76-20.70)$ & $10.66(3.90-22.20)$ & 0.589 \\
PG at 8th day & $13.88(3.67-24.42)$ & $12.76(9.20-46.00)$ & 0.273 \\
\hline
\end{tabular}

PG: Progesterone 


\section{Discussion}

The effect of progesterone support during the luteal phase and luteal serum progesterone values on the success of FET cycles were assessed in several studies. Yovich et al. (2) reported that optimal serum progesterone levels increased implantation rates. Alsbjerg et al. (3) defined a minimum value of $35 \mathrm{nmol} / \mathrm{l}$ for serum progesterone at FET cycles and suggested that values lower than this level decreased pregnancy rates. Labarta et al. (4) denoted that low progesterone levels at transfer day decreased pregnancy rates in donation cycles. However, they could not find a statistically significant upper limit for progesterone, though, they suggested individualizing administration route and dose of progesterone. They further presented similar findings of another study with a large population of non-selected patients and also demonstrated the benefits of administering subcutaneous progesterone in addition to vaginal administration to achieve successful results (11). These results were further empowered by the data, showing the reproducibility of results regarding serum progesterone levels in a subsequent cycle, which was reported at ESHRE (European Society of Human Reproduction and Embryology) 2019 meeting $(11,12)$. Thomsen et al. (5) reported that high luteal progesterone levels, similar to that of low levels, poorly affected treatment outcomes in fresh cycles, and recommended individualized luteal phase support according to early and mid-luteal serum progesterone monitorization. Based on these studies, we evaluated the effect of individualized luteal phase support on pregnancy outcomes.

As for the route, dosage, and timing of progesterone applications for luteal phase support, a consensus has not been reached $(8,13)$. In cycles with hormonal replacement, although it is not clear why serum progesterone values are different on transfer day despite the same treatment dose and route, the rate of vaginal absorption, which may be altered by vaginal discharge or sexual intercourse might affect serum progesterone values $(9,14)$. The effect of administration of vaginal, oral, and intramuscular progesterone was compared in several studies with inconsistent results. While the effects of vaginal and intramuscular routes were found to be similar in some studies $(6,7)$, other studies indicated that intramuscular application improved pregnancy outcomes $(8,15)$. Michnova et al. (16) used vaginal progesterone for luteal support, vaginal application was preferred due to its direct uterine effect, and easy application, and has no adverse outcomes such as allergic reactions. They compared the different types of vaginal micronized progesterone applications and concluded that all were similar in terms of effectiveness and safety, however gel form was tolerated better.

On the other hand, Devine et al. (8), in their study using vitrified blastocysts, compared the effect of vaginal progesterone alone, vaginal and intramuscular progesterone in combination, and intramuscular progesterone alone on pregnancy rates. Vaginal progesterone alone arm was terminated due to poor pregnancy outcomes. However, serum progesterone levels were not measured in these studies.

Paulson et al. (17) reported that the efficiency of oral progesterone was mostly affected by the first-pass effect of liver metabolism. On the other hand, serum progesterone concentrations after intramuscular application were higher than the values reached by vaginal application, even though; serum concentrations were not correlated with the endometrial effect. Progesterone is mostly absorbed by the endometrium after vaginal application, and only a little amount goes to the systemic circulation. However, it is emphasized that low systemic bioavailability does not indicate low biologic efficacy.

In a recent study by Cedrin-Durnerin et al. (9), the dose of applied vaginal progesterone was increased when transfer day progesterone was under the threshold value, by this intervention, serum values two days later were partially increased, however, clinical outcomes were not affected significantly. In this study, however, it is denoted that progesterone could also be administered by different routes.

In our study, the intramuscular route was used for additional progesterone administration for the patients who had low transfer day progesterone values, based on the study of Paulson et al. (17), who denoted that increasing dose of vaginal progesterone did not increase systemic progesterone concentrations in the same ratio, and additional progesterone at high doses may not change the absorbed amount, and Devine et al. (8), who reported that intramuscular progesterone was more effective for luteal support.

In the study of Cedrin-Durnerin et al. (9), vaginal progesterone dose was increased in patients whose transfer day progesterone was below the threshold, and progesterone level higher than $10 \mathrm{ng} / \mathrm{mL}$ was obtained 2 days later at $69 \%$ of the patients, however, outcomes of these patients were not significantly different from the patients whose progesterone value remained below $10 \mathrm{ng} / \mathrm{mL}$. Our results are consistent with this report. Though in the same study, it is denoted that measuring progesterone at transfer day may not be sufficient and it should be monitored as early as two days after initiation of progesterone administration to improve treatment success (9).

In our study, mid-luteal progesterone values after intramuscular progesterone dose were not found to be significantly different between the groups whose transfer day progesterone values were below and above $10 \mathrm{ng} / \mathrm{mL}$, which may indicate the benefit of additional progesterone administration. On the other hand, values higher than $10 \mathrm{ng} / \mathrm{mL}$ on transfer day were not associated with pregnancy rates. While mid-luteal progesterone increased above $10 \mathrm{ng} / \mathrm{mL}$ after an additional dose in $83.3 \%$ of the patients with low progesterone at transfer day, these increased values did not affect pregnancy outcomes significantly either. Although pregnancy achievement rates tended to be 
higher in patients whose mid-luteal progesterone values were above $10 \mathrm{ng} / \mathrm{mL}$, this result was not statistically significant, which may be related to the small sample size of the study.

Different threshold values for progesterone were suggested in several studies (2-5). Furthermore, too high progesterone values were also thought to cause poor pregnancy outcomes (2). In our study, mid-luteal progesterone values were found to remain lower than the ceiling limits, which were reported in previous studies except for one patient who achieved pregnancy despite high mid-luteal progesterone levels (46 ng/mL). Different administration routes may also affect serum levels. In our study, we preferred the intramuscular route for an additional dose of progesterone, to monitor serum values and to observe the efficacy in addition to the vaginal route. We also observed that a single dose was tolerated well by the patients.

Prospective design and a novel dose adjustment for progesterone are the strengths of the study, while a small sample size is a major limitation. Additional dose administration to all patients whose transfer day progesterone was lower than 10 $\mathrm{ng} / \mathrm{mL}$ may raise doubts about pregnancy outcomes, which might be reached in case of the additional intervention was not performed. However, our main interest was the relationship between appropriate progesterone levels and pregnancy rates.

In conclusion, although our study is a preliminary report, to our knowledge, this is the first study in which vaginal progesterone treatment was supported by intramuscular progesterone in case of low serum progesterone values for individualized progesterone application. However, our study did not demonstrate a significant difference in pregnancy outcomes by this method of individualized progesterone administration. Further studies by large populations are needed to optimize the management of hormonally treated FET cycles in terms of luteal support and improve the outcomes.

\section{Acknowledgments: None}

Conflict of interest: The authors report no conflict of interest Funding: This research did not receive any specific grant from funding agencies in the public, commercial, or not-for-profit sectors.

Author contribution: GDD: Manuscript writing, data processing, GB: Data processing, ET: Data collection, HG: Data collection, MS: Data collection, YEŞ: Data processing, statistical analysis, BÖ:Supervision, manuscript editing, CA:Supervision, manuscript editing, MS: Project design, supervision, manuscript editing.

\section{References}

1. Mackens S, Santos-Ribeiro S, van de Vijver A, Racca A, Landuyt LV, Tournaye H, et al. Frozen embryo transfer: a review on the optimal endometrial preparation and timing. Hum Reprod. 2017;32(11):2234-42. Doi: 10.1093/humrep/dex 285 .
2. Yovich JL, Conceicao JL, Stanger JD, Hinchliffe PM, Keane KN. Mid-luteal serum progesterone concentrations govern implantation rates for cryopreserved embryo transfers conducted under hormone replacement. Reprod BioMed Online. 2015;31(2):180-91. Doi: 10.1016/j.rbmo. 2015.05.005.

3. Alsbjerg B, Thomsen L, Elbaek HO, Laursen R, Povlsen BB, Haahr T, et al. Progesterone levels on pregnancy test day after hormone replacement therapy-cryopreserved embryo transfer cycles and related reproductive outcomes. Reprod Biomed Online. 2018;37(5):641-7. Doi: 10.1016/ j.rbmo.2018.08.022.

4. Labarta E, Mariani G, Holtmann N, Celada P, Remohi J, Bosch E. Low serum progesterone on the day of embryo transfer is associated with a diminished ongoing pregnancy rate in oocyte donation cycles after artificial endometrial preparation: a prospective study. Hum Reprod. 2017;32(12):2437-42. Doi: 10.1093/humrep/dex316.

5. Thomsen LH, Kesmodel US, Erb K, Bungum L, Pedersen $\mathrm{D}$, Hauge $\mathrm{B}$, et al. The impact of luteal serum progesterone levels on live birth rates - a prospective study of 602 IVF/ICSI cycles. Hum Reprod. 2018;33(8):1506-16. Doi: 10.1093/humrep/dey226.

6. Shapiro DB, Pappadakis JA, Ellsworth NM, Hait HI, Nagy ZP. Progesteron replacement with vaginal gel versus i.m. injection: cycle and pregnancy outcomes in IVF patients receiving vitrified blastocysts. Hum Reprod. 2014;29(8):1706-11. Doi: 10.1093/humrep/deu121.

7. Berger BM, Phillips JA. Pregnancy outcomes in oocyte donation recipients: vaginal gel versus intramuscular injection progesterone replacement. J Assist Reprod Genet. 2012;29(3):237-42. Doi: 10.1007/s10815-011-9691-9.

8. Devine K, Richter KS, Widra EA, McKeeby JL. Vitrified blastocyst transfer cycles with the use of only vaginal progesterone replacement with Endometrin have inferior ongoing pregnancy rates: results from the planned interim analysis of a three-arm randomized controlled noninferiority trial. Fertil Steril. 2018;109(2):266-75. Doi: 10.1016/j.fertnstert.2017.11.004.

9. Cedrin-Durnerin I, Isnard T, Mahdjoub S, Sonigo C, Seroka A, Comtet M, et al. Serum progesterone concentration and live birth rate in frozen-thawed embryo transfers with hormonally prepared endometrium. Reprod Biomed Online. 2019;38(3):472-80. Doi: 10.1016/j. rbmo. 2018.11.026.

10. Gaggiotti-Marre S, Martinez F, Coll L. Garcia S. Alvarez M, Parriego M, et al. Low serum progesterone the day prior to frozen embryo transfer of euploid embryos is associated with significant reduction in live birth rates. Gynecol Endocrinol. 2019;35(5):439-42. Doi: 10.1080/ 09513590.2018 .

11. Labarta E. A Modern Approach to Progesterone Supplementation. EMJ Repro Health. 2019;5(1):34-7.

12. Labarta Demur E. The artificial endometrial preparation 
for embryo transfer: The litmus test for a sex steroid regimen? Abstract O-146. 35 $5^{\text {th }}$ Annual ESHRE Meeting, 2426 June, 2019.

13. Toth TL, Vaughan DA. Optimizing luteal support in frozen embryo transfer cycles. Fertil Steril. 2018;109(2): 242-3. Doi: 10.1016/j.fertnstert.2017.12.008.

14. Merriam KS, Leake KA, Elliot M, Matthews ML, Usadi RS, Hurst BS. Sexual absorption of vaginal progesterone: a randomized control trial. Int J Endocrinol. 2015;2015: 685281. Doi: 10.1155/2015/685281.

15. Feinberg EC, Beltsos AN, Nicolaou E, Marut EL, Uhler ML. Endometrin as luteal phase support in assisted repro- duction. Fertil Steril. 2013;99(1):174-8. Doi: 10.1016/j.f ertnstert.2012.09.019.

16. Michnova L, Dostal J, Kudela M, Hamal P, Langova K. Vaginal use of micronized progesterone for luteal support. A randomized study comparing Utrogestan ${ }^{\circledR}$ and Crinone ${ }^{\circledR}$ 8. Biomed Pap Med Fac Univ Palacky Olomouc Czech Repub. 2017;161(1):86-91. Doi: 10.5507/bp.2017.007.

17. Paulson RJ, Collins MG, Yankov VI. Progesterone Pharmacokinetics and Pharmacodynamics with 3 dosages and 2 regimens of an effervescent micronized progesterone vaginal insert. J Clin Endocrinol Metab. 2014;99(11):4241-9. Doi: 10.1210/jc.2013-3937. 